\title{
TOLERANSI TANAMAN LANSKAP TERHADAP PENCEMARAN UDARA DI KOTA SIDOARJO
}

\section{Air Pollution Tolerance of Landscape Plants in Sidoarjo City}

\author{
Sylvia Hasna Salsabila \\ Jurusan Agroteknologi, \\ UPN Veteran Jatim \\ Email: hasnasylvia@gmail.com
}

\section{Pangesti Nugrahani}

Jurusan Agroteknologi, UPN Veteran Jatim

Email: pangesti_n@upnjatim.ac.id

\section{Juli Santoso}

Jurusan Agroteknologi,

UPN Veteran Jatim

Email: julisantoso@upnjatim.ac.id

\begin{abstract}
Landscape plant has a few functions, such as for aesthetics plant, giving shade on the road, hedges and absorbing air pollution. Judging from its existence, landscape plants are often facing problem, such as clash with air pollution, as a result of the process of photosynthesis on the plants are disrupted. This research is conducted in two locations in Sidoarjo City, at the Alun-alun Sidoarjo area as the control location (LO) and Aloha area as the polluted location (L1). Method to determine tolerance level through calculation of APTI (Air Pollution Tolerance Index) with parameters of leaf $p H$, water content, ascorbic acid and chlorophyll. The results show that Aerva sanguinolenta has the highest APTI value reached 39.34 at LO and Pterocarpus indicus has 37.08 at L1. Meanwhile, Saraca asoca has the lowest value 10.37 at L1. The difference balue of APTI show the tolerance level of landscape plant to adapt in highly stress condition.
\end{abstract}

Keywords: air pollution, APTI, landscape plants, plant tolerance

Diajukan: 14 Agustus 2020

Diterima: 30 September 2020

\section{PENDAHULUAN}

Tanaman lanskap merupakan kelompok tanaman yang mempunyai banyak fungsi, seperti untuk keindahan, sebagai tanaman peneduh jalan, tanaman pagar dan tanaman penyerap polusi. Ditinjau dari keberadaannya, tanaman lanksap merupakan tanaman yang sering mengalami masalah, seperti masalah yang berbenturan dengan pencemaran udara, akibatnya proses fotosintesis pada tanaman terganggu. Proses fotosintesis terganggu akibat penurunan kadar klorofil yang diakibatkan oleh tingginya polusi udara. Efek pencemaran udara terhadap tumbuhan berdampak pada kerusakan morfologis dan fisiologi tumbuhan. Pencemaran udara dapat mengakibatkan perubahan fisik maupun kimia, selain itu juga dapat mengakibatkan stres fisiologi serta mengancam kehidupan suatu mahluk hidup termasuk tanaman (Zakaria, 2013).

Tanaman dapat digunakan sebagai bioremedian yang dapat mengurangi tingkat pencemaran udara, karena tanaman dapat menyerap berbagai polutan seperti $\mathrm{CO}$, $\mathrm{NO}, \mathrm{NO}_{2}, \mathrm{SO}_{3}, \mathrm{HF}$, dan $\mathrm{O}_{3}$ (Nurfaida dan Yanti, 2011). Namun, tidak semua jenis tanaman dapat menyerap polutan secara efisien, karena perbedaan tingkat toleransinya. Kemampuan tanaman sebagai pereduksi polutan dipengaruhi oleh beberapa faktor, diantaranya faktor lingkungan, model penataan tanaman, fisiologi dan sifat morfologis tanaman (Irianto, 2015).

Penelitian ini dilakukan di Kota Sidoarjo karena kota ini mengalami perkembangan pesat. Sebelum masuknya industri modern, wilayah Sidoarjo dulunya adalah wilayah pertanian dan pertambakan. Sekarang Kota Sidoarjo menjadi kota dengan jumlah pabrik yang cukup banyak.

Berdasarkan dari pemikiran tersebut dan data ambien udara dari Dinas Lingkungan Hidup Sidoarjo, kualitas udara di Sidoarjo dirasa semakin memburuk. Apabila kualitas udara buruk akan mempengaruhi tingkat polusi udara yang dapat membahayakan mahluk hidup khususnya tanaman tepi jalan.

Metode untuk mengetahui tingkat toleransi suatu tanaman terhadap polusi udara dapat diketahui melalui perhitungan APTI (Air Pollution Tolerance Index) dengan parameter $\mathrm{pH}$ daun, kadar air, asam askorbat dan klorofil total (Kurniati dan Irwanto, 2015). Nilai APTI dapat digunakan untuk membantu mengelompokkan tanaman berdasarkan tingkat toleransinya agar menjadi acuan rekomendasi penanaman yang baik.

Salah satu fungsi tanaman yang paling penting adalah dapat menyerap polutan. Upaya menanggulangi pencemaran logam berat dapat dilakukan dengan memanfaatkan kemampuan tumbuhan sebagai penyerap logam. Biosorpsi dan akumulasi zat polutan oleh tumbuhan dapat terjadi melalui tiga proses yaitu, biosorpsi logam oleh akar, translokasi zat pencemar dari akar ke bagian batang atau daun untuk menjaga agar tidak menghambat metabolisme tumbuhan (Nurhikmah, 2015).

Bagian tanaman yang berfungsi sebagai penyerap polutan terutama adalah bagian tajuk tanaman, terutama daunnya. Proses pengurangan polutan dapat dilakukan dengan dua cara yaitu diserap (absorp) atau dijerap (adsorp) masuk ke struktur daun melalui stomata. Distribusi stomata sangat berhubungan dengan kecepatan dan intensitas transpirasi pada daun, yaitu misalnya letak satu sama lain dengan jarak tertentu. Dalam batas tertentu, maka makin banyak porinya makin cepat menguap. Penguapan dapat membantu mengurangi polusi udara melalui deposisi partikulat pada permukaan vegetasi, maupun dengan mekanisme pertukaran gas pada stomata terhadap pengurangan polutan gas. Jika lubang-lubang itu terlalu berdekatan, maka penguapan dari lubang yang satu akan menghambat penguapan lubang di dekatnya (Hariyanti, 2010). Hal ini menujukkan peran dan fungsi tanaman terhadap polusi udara. 


\section{METODE PENELITIAN}

\section{Waktu dan Tempat}

Penelitian ini di Kota Sidoarjo dilakukan pada bulan Desember 2018 sampai Februari 2019 di Laboratorium Bioteknologi Tanaman UPN "Veteran" Jawa Timur, sedangkan pengambilan sampel dilakukan pada tanaman lanskap yang terletak di Kota Sidoarjo, yaitu lokasi sebagai kontrol adalah kawasan Alun-alun Sidoarjo (L0) dan lokasi terpolusi adalah kawasan Aloha Sidoarjo (L1). Tanaman sampel diambil berdasarkan lokasi tanaman yang di dekat jalan raya.

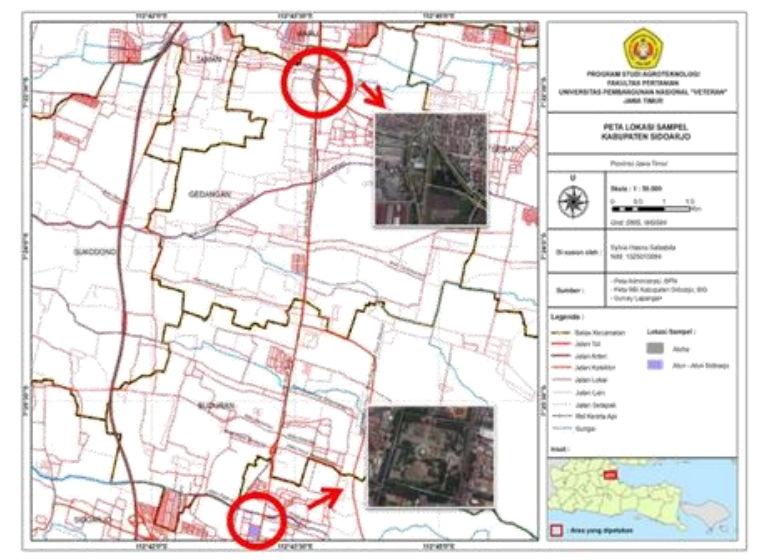

Gambar 1. Lokasi Kontrol (Alun-alun) dan Lokasi Terpolusi (Aloha).

\section{Alat dan Bahan}

Alat dan bahan untuk menunjang penelitian ini adalah kamera, sketch book, komputer, cuvet, spektrofotometer, $\mathrm{pH}$ meter, saringan, kertas sampul, sentrifuge, mortar, oven, pipet, gelas ukur, gelas beaker, erlenmeyer, corong, gunting pangkas dan timbangan digital. Bahan penelitian berupa daun segar tanaman lanskap, aquades, asam askorbat murni 99\%, 2,6 Dichlorophenolindophenol (DCPIP), asam oxalat dan natrium bikarbonat.

Rumus $\mathrm{APTI}=[\mathrm{A}(\mathrm{T}+\mathrm{P})+\mathrm{R}] / 10$, dimana: $\mathrm{A}=$ asam askorbat, $\mathrm{P}=\mathrm{pH}$ daun, $\mathrm{T}=$ total klorofil, $\mathrm{R}=$ kadar air daun. Tanaman memiliki tingkat kadar parameter klorofil, $\mathrm{pH}$, kadar air dan asam askorbat yang berbeda-beda tergantung dari fisiologi tumbuhan itu sendiri (Sumangala et al, 2018).

Tabel 1. Kriteria APTI (Air Pollution Tolerance Index) (Kurniati dan Irwanto, 2015)

\begin{tabular}{cc}
\hline Kriteria & Nilai APTI \\
\hline Sensitif & $<1$ \\
Sedang & $1-16$ \\
Cukup Toleran & $17-29$ \\
Toleran & $30-100$ \\
\hline
\end{tabular}

Kriteria yang digunakan untuk vegetasi adalah jumlah tanaman yang mencukupi, tumbuhan yang sudah dewasa atau bukan anakan, dan tersedia di lokasi yang digunakan untuk sampel. Tanaman yang digunakan dalam penelitian berbeda-beda kelompoknya, terdiri dari penutup tanah, perdu, semak dan pohon. Sampel yang digunakan masing-masing terdiri dari dua lokasi yaitu kontrol dan terpolusi dengan tiga ulangan setiap sampelnya.

\section{Penentuan Kadar Klorofil total}

Klorofil total daun diukur dengan spektrofotometer dengan langkah awal memotong kecil daun sampel. Daun segar tanaman sampel sebanyak 0,5 gr dihancurkan lalu diekstrak dengan aceton $80 \%$ sebanyak 50 ml. Kemudian menyaring larutan dan memasukkannya ke dalam cuvet setrifuge. Larutan tersebut disentrifugasi selama 3 menit dengan kecepatan $2500 \mathrm{rpm}$. Selanjutnya menghitung kadar klorofil total daun dengan membandingkan pada panjang gelombang $645 \mathrm{~nm}$ dan $663 \mathrm{~nm}$ dengan rumus: $\mathrm{Ct}$ $=20.2($ D645) $+8.02($ D663) (Veni et al, 2014)

\section{Penentuan pH Daun}

Berdasasarkan penelitian Agbaire dan Esiefarienrhe (2009) derajat keasaman atau $\mathrm{pH}$ daun diukur agar menggunakan $\mathrm{pH}$ meter dengan menghancurkan $5 \mathrm{~g}$ daun segar didalam $100 \mathrm{ml}$ aquades. Menyaring ekstrak daun lalu disentrifugasi $2.500 \mathrm{rpm}$ selama 10 menit. Lalu larutan tersebut diukur dengan $\mathrm{pH}$ meter.

\section{Penentuan Konsentrasi Asam Askorbat}

Analisa perhitungan asam askorbat menggunakan metode titrasi DCPIP (Anjali et al, 2012). Bahan pertama membuat $4 \%$ asam oksalat (4 g asam oksalat dilarutkan dalam 100 $\mathrm{ml}$ aquades), kemudian membuat larutan DCPIP (53 mg DCPIP dan $42 \mathrm{mg}$ natrium bikarbonat dilarutkan dalam $200 \mathrm{ml}$ aquades). Membuat larutan stok asam askorbat (100 mg asam askorbat dilarutkan dalam $100 \mathrm{ml}$ asam oksalat $4 \%$ dalam labu standar). Jaringan segar (50 mg daun) ditumbuk lalu diberi larutan asam oksalat $(5 \mathrm{ml})$ dan kemudian disaring.

Setelah semua larutan dibuat, larutan kerja asam askorbat (disiapkan dengan melarutkan $10 \mathrm{ml}$ larutan stok menjadi $100 \mathrm{ml}$ dengan bantuan aquades) diambil $10 \mathrm{ml}$ lalu campurkan larutan sampel sebanyak $5 \mathrm{ml}$ kemudian diletakkan pada elenmeyer. Sebesar $10 \mathrm{ml}$ asam oksalat (4\%) ditambahkan kedalamnya dan dititrasi terhadap diklorofenol indofenol (DCPIP) hingga berwarna merah muda yang bertahan selama beberapa menit, dianggap sebagai titik akhir. Kemudian hitung kadarnya dengan rumus:

$$
\mathrm{AA}=\frac{0,5}{V 1} \times \frac{V 2}{5} \times \frac{100}{\mathrm{~W}}
$$

Keterangan:

V1: volume awal (ml)

V2: volume titrasi $(\mathrm{ml})$

$\mathrm{W}$ : berat sampel $(\mathrm{mg})$

\section{Penentuan Kadar Air Tanaman}

Berdasasarkan penelitian Agbaire dan Esiefarienrhe (2009) sampel daun dikeringkan dalam oven pada suhu $80^{\circ} \mathrm{C}$ selama 48 jam untuk menghilangkan air. Kadar air daun diukur berdasarkan metode gravimetri dengaan rumus:

$$
\operatorname{Kadar} \operatorname{Air}(\%)=\frac{\mathrm{bb}-\mathrm{bk}}{\mathrm{bb}} \times 100
$$

Keterangan:

$\mathrm{bb}=$ berat basah

$\mathrm{bk}=$ berat kering 


\section{HASIL DAN PEMBAHASAN}

Setiap tanaman memiliki tingkat toleransi terhadap pencemaran udara yang berbeda-beda. Berdasarkan hasil penelitian yang telah dilakukan, tanaman dapat bertahan hidup dengan nilai toleransi terhadap pencemaran udara yang berbeda-beda berdasarkan pada kriteria yang dihitung dengan rumus APTI dengan beberapa komponen penyusun nilainya seperti $\mathrm{pH}$, kadar air, asam askorbat dan klorofil.

Hasil analisa Agbaire (2009) menunjukkan bahwa tanaman yang stres bertindak defensif dengan meningkatkan atau menurunkan kadar air relatifnya, asam askorbat konten, kandungan total klorofil dan $\mathrm{pH}$ untuk membantu tanaman mempertahankan keseimbangan fisiologisnya di bawah tekanan kondisi yang disebabkan oleh polutan udara.

\section{Asam Askorbat}

Tanaman Pterocarpus indicus memiliki kadar asam askorbat tertinggi pada lokasi terpolusi sebesar 10,764 $\mathrm{mg} / \mathrm{g}$ dan pada daerah kontrol sebesar 10,196 mg/g. Tingginya nilai asam askorbat membuat tanaman ini memiliki toleransi tanaman yang baik dan tergolong toleran. Berbeda dengan tanaman Bougainvillea yang memiliki kadar asam askorbat yang rendah sebesar 2,973 $\mathrm{mg} / \mathrm{g}$ pada lokasi terpolusi. Hal ini menujukkan tanaman Bougainvillea mempunyai tingkat toleransi yang rendah dengan kriteria toleransi sedang. Berdasar pada penelitian Dwiputri (2018), formulasi APTI menunjukkan bahwa perubahan asam askorbat memberikan pengaruh yang paling baik dibandingkan dengan parameter lain seperti klorofil total, pH ekstrak daun, dan kadar air daun. Menurut Zhang et al. (2016) asam askorbat mempengaruhi toleransi terhadap polusi udara pada tanaman, karena mengaktifkan banyak aktivitas fisiologis dan mekanisme pertahanan dalam tanaman. Asam askorbat dapat bertindak sebagai donor elektron untuk berbagai enzim dan reaksi non-enzimatik, reduksi agen, dan antioksidan. kondisi tepolusi. Sedangkan tanaman Saraca asoca memiliki kadar air terendah pada lokasi terpolusi yaitu sebesar 51,36\%. Tanaman Saraca asoca mempunyai tingkat toleransi terendah. Menurut Bakiyaraj dan Ayyappan (2014) mengatakan bahwa polusi udara meningkatkan permeabilitas sel, menyebabkan hilangnya air dan nutrisi terlarut.

\section{Derajat Keasaman $(\mathrm{pH})$}

Tanaman Aerva sanguinolenta memiliki kandungan $\mathrm{pH}$ tertinggi pada lokasi terpolusi yaitu sebesar 7,27, sedangkan tanaman Canna indica memiliki $\mathrm{pH}$ yang rendah yitu 5,55. Toleransi tanaman Aerva sanguinolenta berbeda dengan Canna indica. Aerva sanguinolenta memiliki kategori tanaman yang toleran sedangkan Canna indica memiliki tingkat toleransi dalam kategori sedang. Menurut Zuoari et al. (2018) pH memiliki peran penting dalam proses fisiologi tumbuhan, Sebagian besar enzim, yang terlibat dalam aktivitas biologis organisme membutuhkan $\mathrm{pH}$ yang relatif tinggi untuk bekerja dengan baik, sehingga tanaman dengan $\mathrm{pH}$ rendah lebih rentan terhadap polusi sedangkan tanaman dengan $\mathrm{pH} 7$ lebih toleran terhadap polusi.

\section{Klorofil}

Menurut Pada penelitian ini tanaman Aerva sanguinolenta memiliki kandungan klorofil tinggi pada lokasi kontrol sebesar 26,46 mg/g, sehingga tanaman ini termasuk dalam kriteria toleransi tanaman yang tergolong tanaman toleran yang ditunjukkan dengan nilai APTI tertinggi yaitu sebesar 39,34.

\section{Air Pollution Tolerance Index (APTI)}

Toleransi tanaman terhadap pencemaran udara merupakan suatu hal yang setiap hari terjadi dalam tanaman sebagai kemampuan tanaman dalam merespon tekanan lingkungan yang ekstrem dari kondisi normal. Respon pertumbuhan tanaman terganggu akibat cekaman lingkungan seperti pencemaran udara.

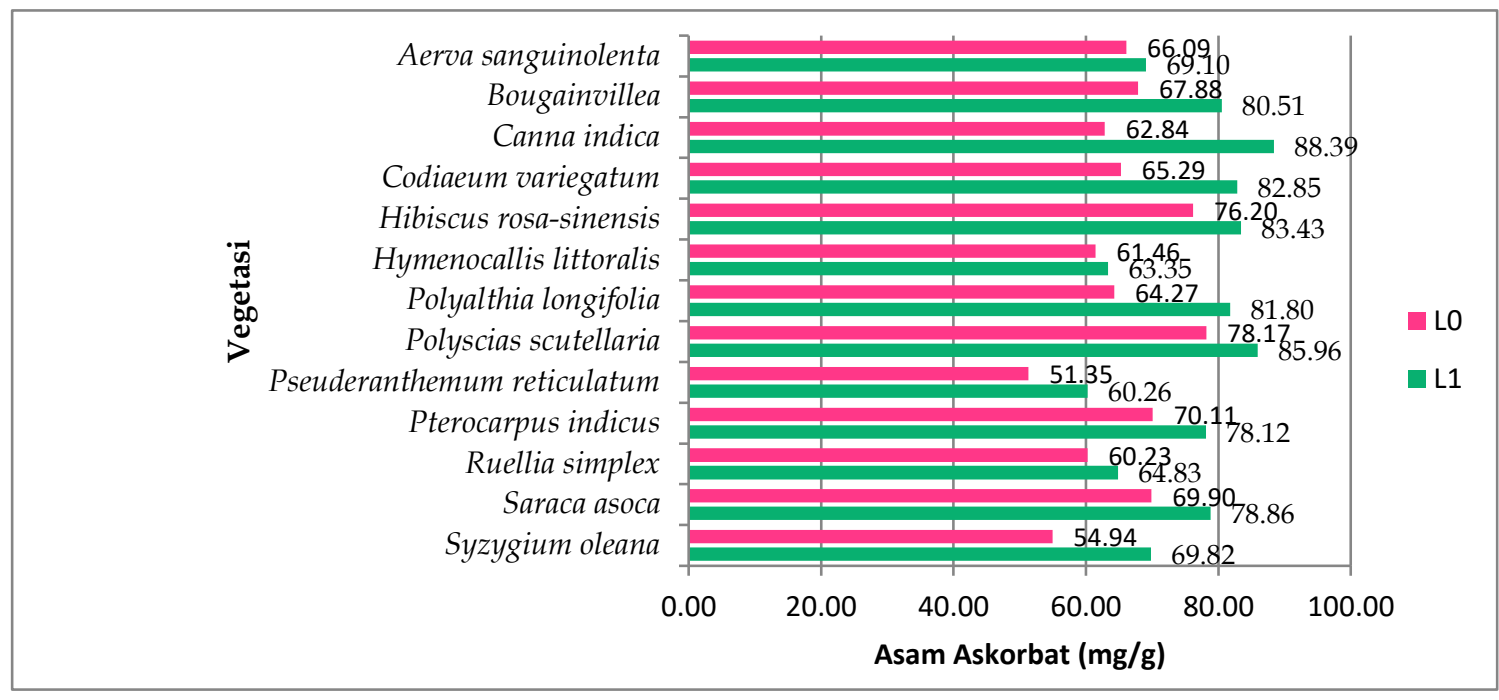

Gambar 2. Kadar Asam Askorbat pada Area Kontrol (L0) dan Terpolusi (L1)

\section{Kadar Air}

Kadar air tanaman juga berpengaruh dalam toleransi suatu tanaman. Kadar air tertinggi diperoleh oleh Pseuderanthemum reticulatum sebesar $88,30 \%$ pada lokasi kontrol dan Aerva sanguinolenta sebesar 78,17\% dalam
Tanaman degan toleransi rendah akan menampakkan kerusakannya secara fisik dan fisiologisnya. Seperti nekrosis bahkan sampai layu dan mengalami kematian 


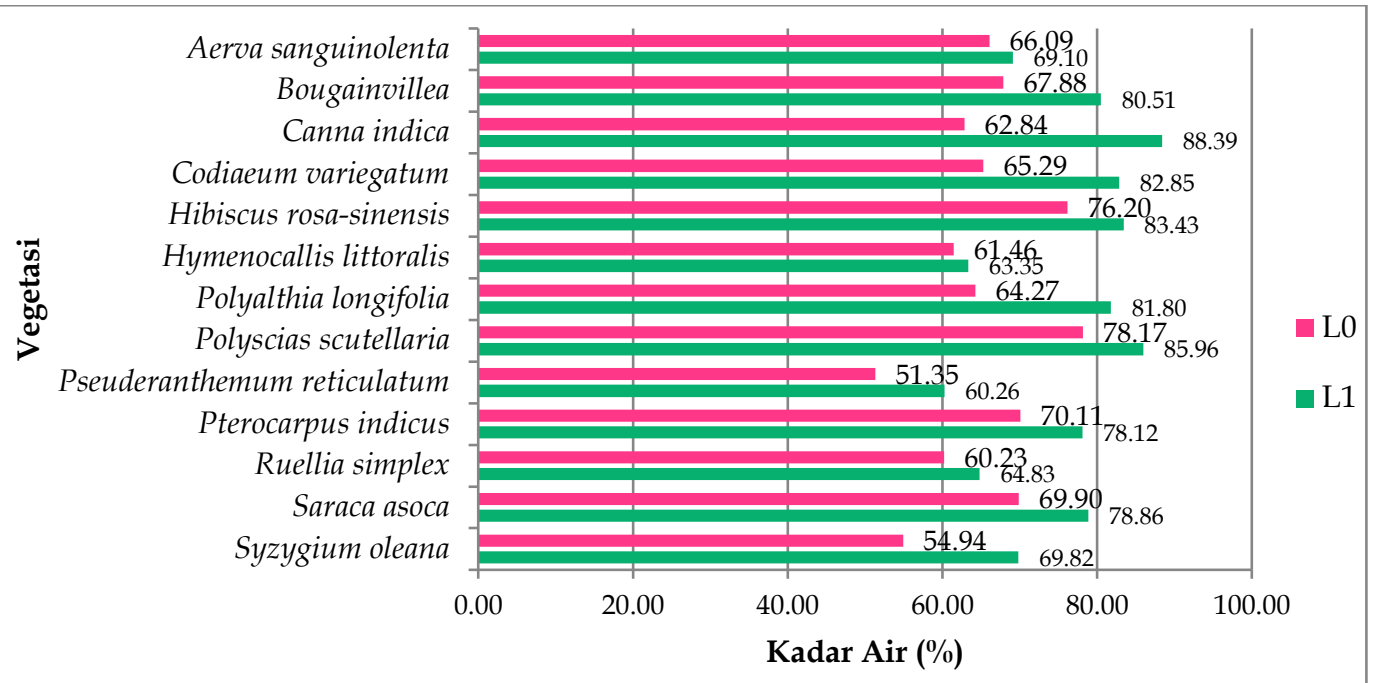

Gambar 3. Presentase Kadar Air pada Area Kontrol (L0) dan Terpolusi (L1)

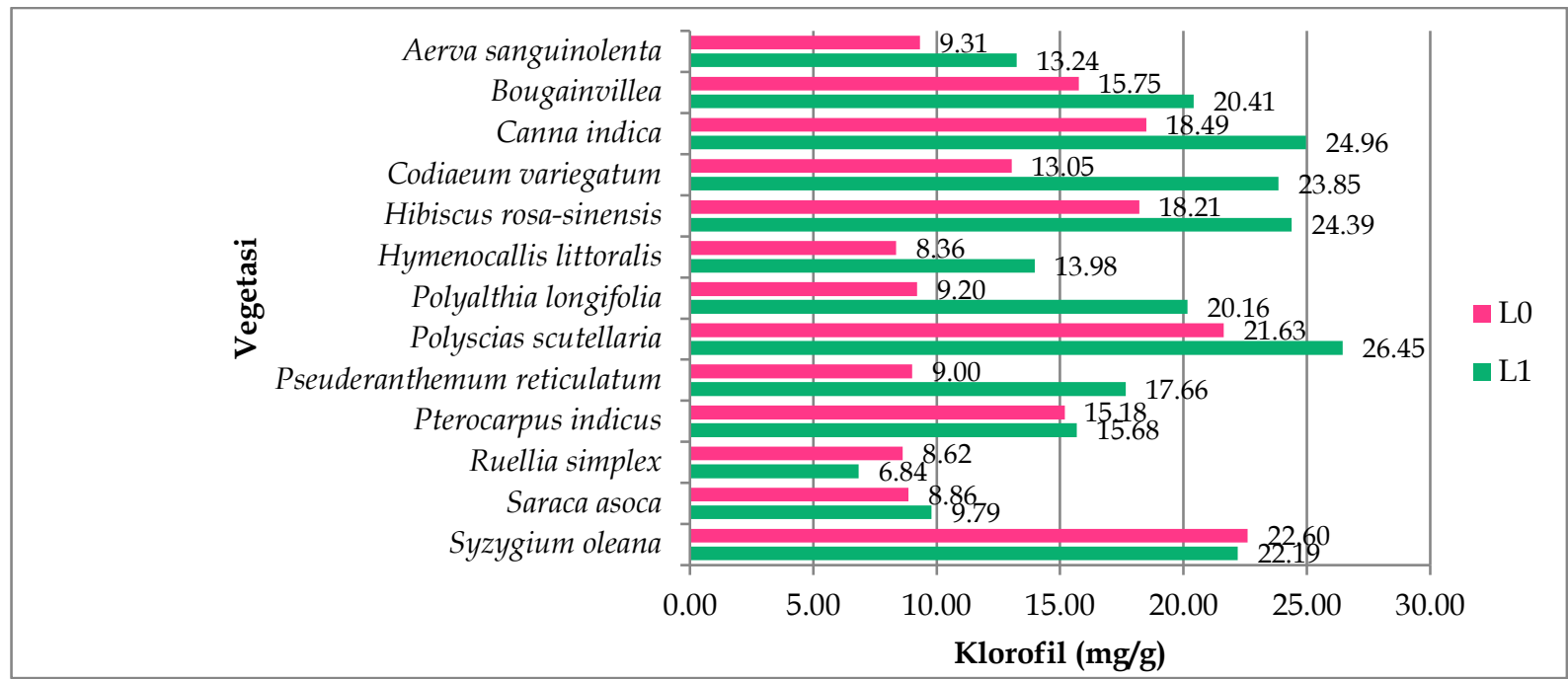

Gambar 4. Kadar pH pada Area Kontrol (L0) dan Terpolusi (L1)

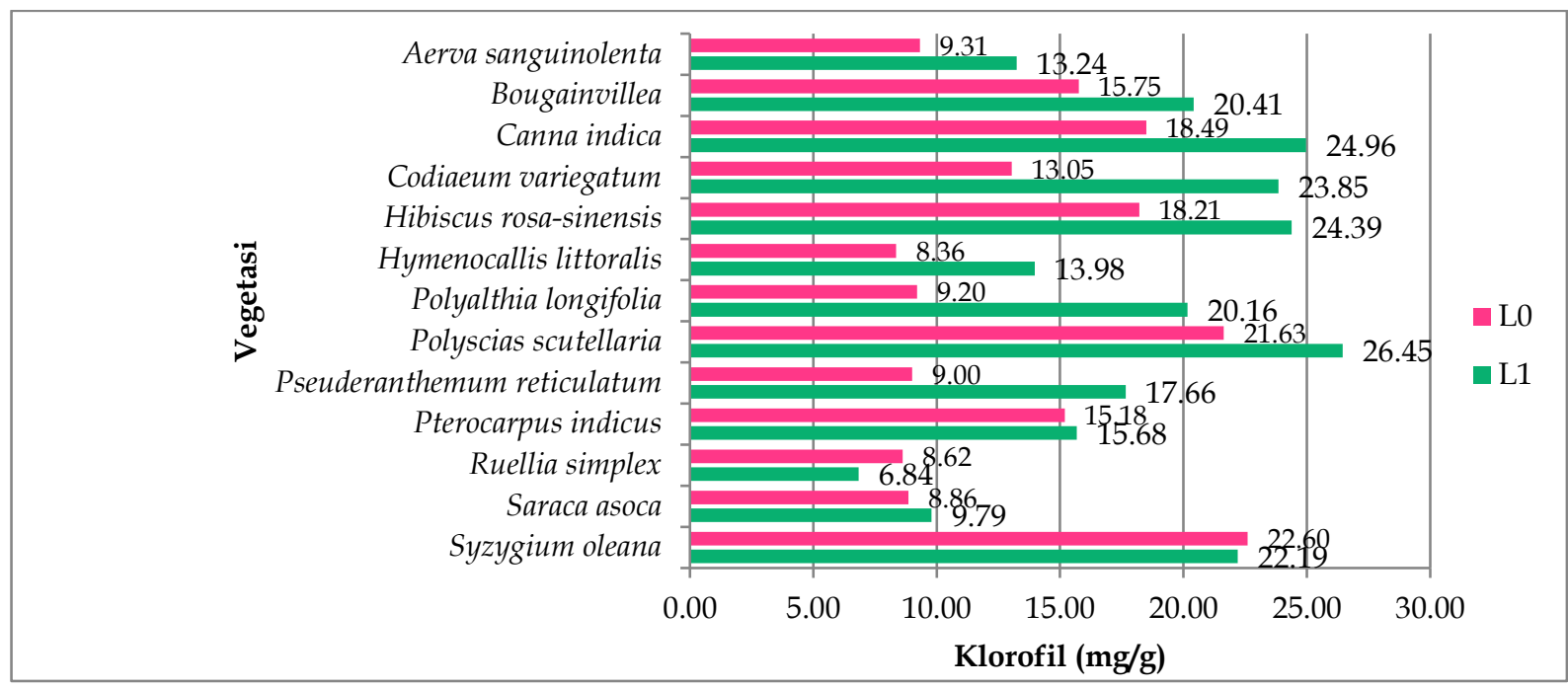

Gambar 5. Kadar Klorofil pada Area Kontrol (L0) dan Terpolusi (L1)

karena tidak tahan dengan lokasi dengan polusi yang tinggi.

Menurut penelitian Dewi (2001), pengaruh hujan asam dengan $\mathrm{pH}$ 2,8 terhadap anakan Akasia berupa gejala kerusakan nekrosis, klorosis dan abnormalitas bentuk daun. Terdapat 25,85\% keabnormalan bentuk daun menjadi melengkung dan mengalami kematian jaringan pada daun.

Tanaman akan kekurangan nutrisi karena limbah yang mencemari tanah telah membunuh organisme pengurai 
bangkai. Organisme tersebut antara lain adalah bakteri, jamur, dan cacing, hingga sisa makhluk hidup, seperti potongan kayu, tumpukan rumput yang tidak bisa diuraikan menjadi anorganik. Tanaman yang tumbuh didaerah dengan tingkat pencemaran tinggi dapat mengalami berbagai gangguan pertumbuhan serta rawan akan berbagai penyakit, antara lain klorosis, nekrosis, dan bintik hitam (Wijianto, 2013). ini terjadi karena lokasi tanaman tersebut sangat berdekatan dengan jalan raya yang diduga perlu kemampuan dan jumlah beberapa komponen fisiologis seperti $\mathrm{pH}$, asam askorbat, kadar air atau klorofil yang tinggi guna mempertahankan dirinya terhadap polusi udara. Tanaman tersebut toleran terhadap polusi udara.

Tanaman dengan APTI tinggi terbukti toleran terhadap

Tabel 2. Tingkat toleransi tanaman terhadap pencemaran udara berdasarkan APTI

\begin{tabular}{llcccc}
\hline \multirow{2}{*}{ No } & \multirow{2}{*}{ Nama Latin } & \multicolumn{2}{c}{ APTI } & \multicolumn{2}{c}{ Tingkat Toleransi } \\
\cline { 3 - 5 } & & L0 & L1 & L0 & L1 \\
\hline 1 & Aerva sanguinolenta & 39,34 & 32,60 & Toleran & Toleran \\
2 & Bougainvillea & 26,47 & 11,17 & Cukup Toleran & Sedang \\
3 & Canna indica & 13,47 & 13,17 & Sedang & Sedang \\
4 & Codiaeum variegatum & 12,76 & 12,33 & Sedang & Sedang \\
5 & Hibiscus rosa-sinensis & 23,01 & 20,39 & Cukup Toleran & Cukup Toleran \\
6 & Hymenocallis littoralis & 20,35 & 19,94 & Cukup Toleran & Cukup Toleran \\
7 & Polyalthia longifolia & 15,63 & 14,88 & Sedang & Sedang \\
8 & Polyscias scutellaria & 28,93 & 25,87 & Cukup Toleran & Cukup Toleran \\
9 & Pseuderanthemum reticulatum & 32,21 & 30,04 & Toleran & Toleran \\
10 & Pterocarpus indicus & 36,20 & 37,08 & Toleran & Toleran \\
11 & Ruellia simplex & 27,78 & 18,69 & Cukup Toleran & Cukup Toleran \\
12 & Saraca asoca & 13,99 & 10,37 & Sedang & Sedang \\
13 & Syzygium oleana & 11,56 & 12,26 & Sedang & Sedang \\
\hline
\end{tabular}

Keterangan: $\mathrm{L} 0=$ Kontrol, L1 $=$ Lokasi terpolutan

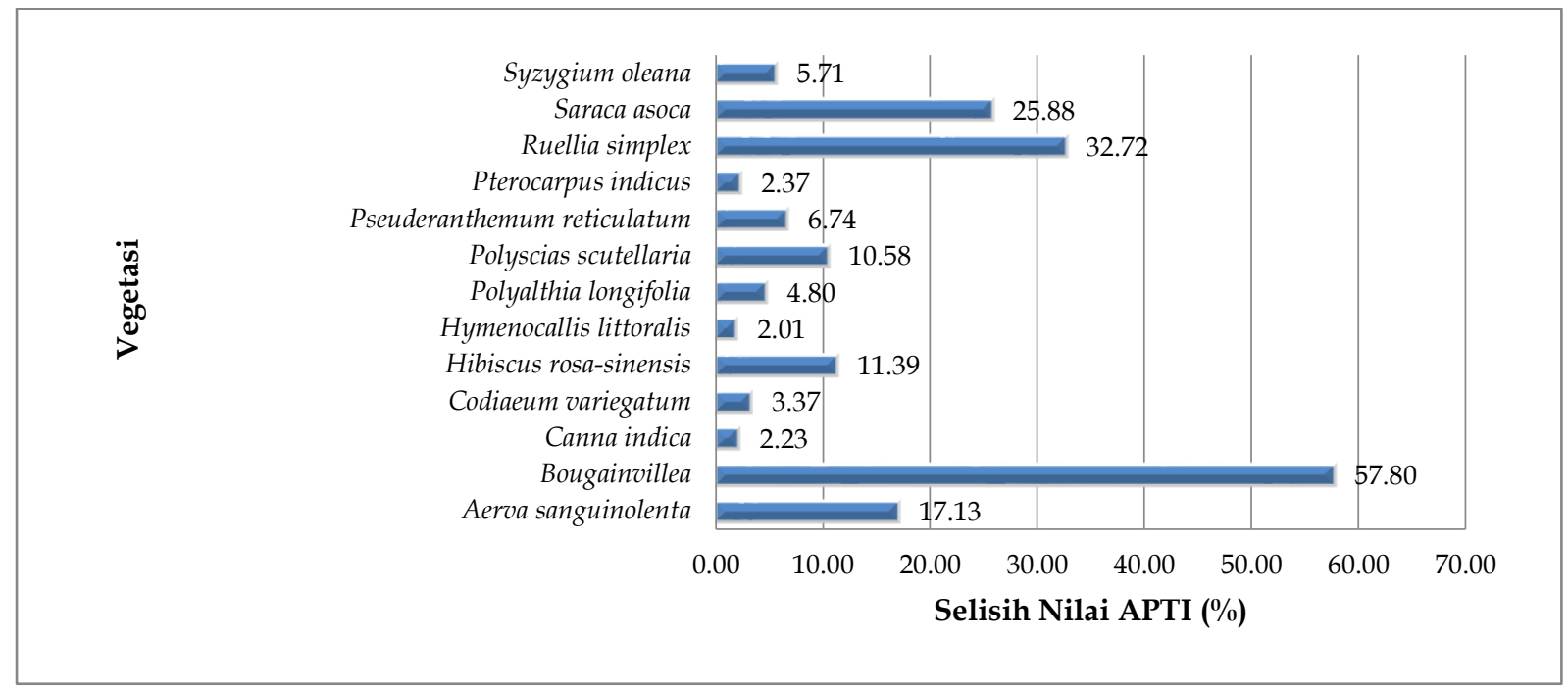

Gambar 6. Selisih Nilai APTI pada Lokasi Terpolusi dan Kontrol

Tanaman yang memiliki nilai APTI tertinggi adalah tanaman Aerva sanguinolenta dengan nilai 39,34 pada lokasi kontrol dengan kriteria toleran. Sedangkan tanaman Saraca asoca memiliki tingkat kriteria toleransi yang sedang dengan nilai sebesar 10,37 pada lokasi terpolusi.

Perbedaan selisih nilai APTI pada setiap tanaman antara lokasi terpolusi dan lokasi kontrol dapat menujukkan kriteria toleransi terhadap tanaman tersebut. Tanaman yang memiliki selisih nilai APTI yang sedikit antara lokasi terpolusi dan lokasi kontrol, menunjukkan tanaman tersebut toleran dalam kondisi terpapar polusi yang tinggi atau rendah, karena tanaman tersebut dapat menyesuaikan diri.

Pada tabel 2 menunjukkan tanaman Pterocarpus indicus dan Syzigium oleana memiliki akumulasi APTI tertinggi pada lokasi terpolusi (L1) dari pada lokasi kontrol (L0), hal polusi udara bertindak sebagai bioakumulator penting dari polutan udara, sedangkan tanaman yang menunjukkan APTI rendah dapat diklasifikasikan sebagai sensitif terhadap pencemaran udara dapat bertindak sebagai bioindikator polusi udara (Rai et al. 2013).

Gambar 6 menunjukkan bahwa tanaman memiliki perbedaan selisih nilai APTI antara lokasi terpolusi dengan kontrol. Banyak atau sedikitnya selisih nilai APTI disebabkan oleh komponen penyusun indeks APTI. Tanaman yang memiliki selisih sedikit, mempunyai kadar komponen penyusun indeks APTI yang tidak berbeda jauh antara tanaman pada lokasi terpolusi dan kontrol, sedangkan pada tanaman yang memiliki persentase selisih banyak memiliki kadar komponen penyusun APTI yang berbeda jauh antara lokasi terpolusi dan kontrol. 


\section{SIMPULAN}

Berdasar pada penelitian yang dilakukan, tanaman Aerva sanguinolenta memiliki APTI tertinggi dengan nilai 39,34 pada lokasi kontrol (L0) dan Pteocarpus indicus dengan nilai 37,08 pada lokasi terpolusi (L1) sedangkan Saraca asoca memiliki APTI terendah dengan nilai 10,37 pada lokasi terpolusi (L1). Selisih nilai APTI setiap tanaman menunjukkan ketahanan suatu tanaman dalam menyesuaikan fisiologi tanaman pada cekaman. Sedangkan klasifikasi tanaman Aerva sanguinolenta, Pseuderanthemum reticulatum dan Pterocarpus indicus merupakan tanaman toleran, tanaman Hibiscus rosasinensis, Hymenocallis littoralis, Polyscias scutellaria, Ruellia simplex termasuk dalam kriteria tanaman yang cukup toleran dan tanaman Bougainvillea sp., Canna indica, Codiaeum variegatum, Polyalthia longifolia, Saraca asoca, dan Syzygium oleana termasuk tanaman dalam kategori tolerasi sedang berdasar hasil penelitian yang telah dilakukan tersebut.

\section{DAFTAR PUSTAKA}

Agbaire, P.O., dan E. Esiefarienrhe. 2009. Air Pollution Tolerance Indices (APTI) of Some Plants Around Otorogun Gas Plant in Delta State, Nigeria. J. Appl. Sci. Environ. Manage Vol. 13(1). 11 - 14.

Anjali, M. Kumar, N. Singh dan K. Pal. 2012. Effect of Sulphur Dioxide on Plant Biochemicals. International Journal of Pharma Professional's Research Vol 3. 538-544

Bakiyaraj, R. and Ayyappan, D. 2014. Air Pollution Tolerance Index Of Some Terrestrial Plants Around An Industrial Area. Int. J. Mod. Res. Rev, 2(1), 1-7.

Dewi, I.S. 2001. Pengaruh Hujan Asam Terhadap Beberapa Jenis Anakan Tanaman Hutan Kota (Studi Pemilihan Jenis-Jenis Pohon Berdasarkan Ketahanan Terhadap Hujan Asam). IPB. Bogor

Dwiputri, D.A. 2018. Developing Plant Tolerance Indicator To Air Pollution, Case Study In Krakatau Industrial Estate Cilegon City, Indonesia. Jurnal Lanskap Indonesia Vol 10 (1), 19-27

Irianto, K. 2015. Buku Bahan Ajar Pencemaran Lingkungan. Universitas Warmadewa: Bali. 88 Halaman

Kurniati, C. dan R.R. Irwanto. 2015. Evaluasi Nilai APTI dan API pada Swietenia macrophylla dan Agathis dammara yang Terdapat di Kampus ITB Ganesha, Bandung. Prosiding Seminar Nasional Masyarakat Biodiversitas Indonesia Vol 1(7). 1610-1614

Nurfaida, Dariati, T. dan Yanti, C.W.B. 2011. Bahan Ajar Ilmu Tanaman Lanskap. Universitas Hasanuddin. Makassar. 27 Halaman

Rai, P.K., L.S. Panda, B.M. Chutia dan Singh. 2013. Comparative Assessment of Air Pollution Tolerance Index (APTI) in the industrial (Rourkela) and Non-Industrial Area (Aizawl) of India: An Ecomanagement Approach. African Journal of Environmental Science and Technology. Vol 7(10) 944948

Sumangala H.P., C. Aswath, R.H. Laxman and M.R. Namratha. 2018. Estimation of Air Pollution
Tolerance Index (APTI) of Selected Ornamental Tree Species of Lalbagh, Bengaluru, India. Journal of Pharmacognosy and Phytochemistry ,7(2): 3894-3898

Veni, K., Marimuthu dan K. Lavanya. 2014. Air Pollution Tolerance Index of Plants a Comparative Study. International Journal of Pharmacy and Pharmaceutical Sciences Vol 6.320-324

Wijianto, Eko. 2013. Validasi Metode Analisis Pb dengan Menggunakan Flame Spektrofotometer Serapan Atom (SSA) untuk Studi Biogeokimia dan Toksisitas Logam Timbal $(\mathrm{Pb})$ pada Tanaman Tomat (Lycopersicum esculentum).Universitas Lampung. Lampung. 69 Halaman

Zakaria, N. 2013. Analisis Pencemaran Udara (SO2), Keluhan Iritasi Tenggorokan dan Keluhan Kesehatan Iritasi Mata pada Pedagang Makanan di Sekitar Terminal Joyoboyo Surabaya. UNAIR. Surabaya. 7 Halaman

Zhang, P. Q., Liu, Y. J., Chen, X., Yang, Z., Zhu, M. H. and Li, Y. P. (2016). Pollution Resistance Assessment of Existing Landscape Plants on Beijing Streets Based on Air Pollution Tolerance Index Method. Ecotoxicol. Environ. Saf., 132, 212-223.

Zouari, M., Elloumi, N., Mezghani, Labrousse, B. Rouina, B. Abdallah, dan B. Ahmed. 2018. A Comparative Study of Air Pollution Tolerance Index (APTI) of Some Fruit Plant Species Growing in the Industrial Area of Sfax, Tunisia. 